\title{
Corpus Functional Stylistic Analysis of Modal Verbs in Major Barbara and Its Chinese Versions
}

\author{
Zan Mao \\ English Department, Zhenjiang Watercraft College, Zhenjiang, China \\ $\mathrm{Na} \mathrm{Li}$ \\ English Department, Zhenjiang Watercraft College, Zhenjiang, China \\ Jiao Xue \\ English Department, Zhenjiang Watercraft College, Zhenjiang, China
}

\begin{abstract}
With modality in systematic functional linguistics as the theoretical framework, we attempt to investigate the distribution and model verbs in Major Barbara and its two Chinese versions by Lin Haozhuang and Ying Ruocheng by the aid of text-processing software AntConc 3.2.2, in the hope of exploring the shaping force of modality system in characterization as well as interpersonal relationships in drama translation. In addition, a valid research model of corpus functional stylistics in drama translation is tentatively conducted.
\end{abstract}

Index Terms-modal verb, drama translation, interpersonal relationship, Major Barbara, Corpus functional stylistics

\section{INTRODUCTION}

George Bernard Shaw created vast and numerous works throughout his life. Major Barbara was one of his most wonderful dramas, which perfectly expressing the writer's artistic characteristic of showing the conflicts between characters and revealing the theme through dialogues. With the change of behaviors and values of the heroine Barbara as the main line, the whole drama is full of drastic ideological confrontations among characters who hold different outlooks on life and values. The language of the characters in his drama is always witty and humorous. Scholars and critics have analyzed it from multiple perspectives such as cognition and pragmatics, but rare investigations have been conducted from functional stylistics. Take the modality system in SFL (Systemic Functional Linguistics) as the theoretical framework, this article has tried to analyze two typical groups of dialogues between three main characters in Major Barbara and its two Chinese versions by Lin Haozhuang and Ying Ruocheng with the stylistic approach based on self-construct corpus by the aid of text-processing software AntConc 3.2.2, to reveal the personality and interactive attitude of the heroes and heroines so that to discover the role relationship and explore the interpersonal function of the modality system for further researching and understanding of the artistic characteristics of the drama.

When considering the modal verbs in the English original version, this article has selected relative corpuses in two Chinese translation versions to achieve parallel and contrastive analysis. The version translated by Lin Haozhuang was first published in 1956, together with Mrs. Warren's Profession translated by Pan Jiaxun and The Apple Cart translated by Lao She, and was published in The Selected Works by Bernard Shaw edited by People's Literature Publishing House and was republished in 1963 in Three Dramas of Bernard Shaw. However, there are few introductions or studies about background of Lin Haozhuang as a translator. On the contrary, the other translator Ying Ruocheng was well-known as a director, actor, translator and politician who always pursuing "promote translation through acting and vice versa" as his aim in drama translation. He was good at combining literary effects with theatrical effects. In 1990, he translated Major Barbara and then put it on to the stage which turned out to be a big success. There are many differences lies between these two Chinese versions of Major Barbara. There existed a big time span between the two versions and were born in a revolution age of Chinese society, and the translators themselves also had significant diversities in life backgrounds. Therefore, by comparing the similarities and differences of the representation of modality system in the two versions of Lin and Ying, we can discover different translator's styles and discuss the construction function of the modality system to characters and interpersonal relationship in the drama as well as to explore the corpus functional stylistics analysis model in drama translation.

\section{The Corpus Functional Stylistics Approaches to Drama Translation Studies}

As Shen Dan (1995) pointed out in the discussion of the relationship of literary stylistics and fiction translation, literary translation should be suitable for stylistic Studies. However, there were rare attempt to apply stylistics into literary translation, at least for Chinese and English. Boase Beier (2004) also found that the research results of stylistics had little effect on translation studies for many years and the views of translation studies had little stylistics factors, 
either. Besides, though corpus stylistics studies emerged rapidly and drastically, both the domestic and foreign studies on the corpus stylistics have obviously placed extra emphasis on fiction narrative styles, failing to pay equal attention to other typical features of styles such as poetry and drama. Thus, the research perspective and related explanation strength of corpus stylistics would be restricted. Even the combination of corpus stylistics and translation studies fails to establish systematic research framework of translation studies and especially drama translation.

\section{A. The Corpus Functional Stylistics and Drama Translation Study}

The drama language is mainly based on character dialogues. As the classical "interactive verbal communication", the dialogues emphasize the language's colloquialism, individuation and action. Therefore, analysis on the drama language should concentrate on the generation and comprehension process of meaning in context and interaction so as to reveal how the dialogues serve for the performance of dramatic conflicts and describe the characters, and finally fulfill the explanatory adequacy (Yu Dongming, 1996). In the 1980s and 1990s, the functional linguistics, pragmatics and discourse analysis developed rapidly and were widely used into the investigation of English drama language. Western scholars such as Carter \& Simpson (1989), Bennison (1993) and Herman (1995) made great efforts in this respect.

Functional stylistics, theoretically based on functionism view of language, is an import school of stylistics theory and has played a more and more crucial part in modern stylistics study. Represented by Halliday's theory, the systematic functional linguistics has the characteristics of functionality, systematicness and pays much attention to situational context in which the textual function would organize the ideational function and interpersonal function as a whole in the discourse. Those three functions are interrelated and motivate each other to be the main ingredients for constituting the "meaning potential". When doing stylistic analysis, the ideational function would start from the transitivity system, voice as well as coordination and subordination in logic relation; the interpersonal function would be achieved by mood and modality system; the textual function would be reflected from the information structure, thematic structure and cohesion system.

We have found that some scholars at home and abroad have devoted themselves to the functional stylistic analysis of drama translation studies in recent year. With the help of corpus means, Kruger $(2000,2004)$ investigated the expression of lexical cohesion, register variants and features of involvement in different linguistic fields of Shakespeare's drama when translated into Afrikkans (a kind of language in South Africa). Ren Xiaofei (2008) made drama stylistic analysis based on the corpus about the construction of the illocutionary force, discourse marker, turn-taking and indicating system in several translations of Tea House, Death of a Salesman and Measure for Measure. Zhang and Chen (2010) chose personalized character language and relative translation of Dream of Red Mansions as the data of corpus, and applied modality system as the entry point to study the selection of modality in discourse and its corresponding interpersonal function in the translation version. Such studies have provided great theoretical and technical support to this research.

\section{B. The Modal System and Its Interpersonal Function in Drama Translation}

Language is a meaningful activity for social men, it is an important medium for interaction with others and establishing and maintaining certain relationship. Functional linguistics holds the view that apart from expressing the speaker's personal experience and inner activity, language can represent the identity, status, attitude, motivation and inference of things, namely the interpersonal function of language. Some systematic functional linguists like Halliday have pointed out that the language interpersonal function consists of mood system, modality system, and key system. In this thesis, modality system is discussed as the main topic.

The characteristics of modality are reflected in many ways and the academic definition for modality is not unified. Besides the modal verbs, the modal adverbs and adjectives in English such as possible, probably, perhaps, obviously, likely, definitely, only, just, really, quite, usually, please, etc.; passive predicate verbs or predicate adjectives like be supposed to, be keen to, and be anxious to etc.; and the metaphorical expressions like I believe, I know, I think, I'm certain, It's likely, you can't seriously doubt that etc. are often used to express some degree of modality, and they constitute the means for the modality system to reflect the interpersonal meaning.

According to the implication of different information, Halliday has further divided the modality into modalisation and modulation. The modalisation analyzes the reliability of the proposition and information from possibility and frequency, including the degrees of probability and usuality; while the modulation refers to the confidence involved in the successful exchanged information from the obligations and willingness, including the degrees of obligation and inclination. In each element, the corresponding modal realizations can be reflected and considered through related means. As shown in Table 1, the realizations of modality can be divided into low, medium and high (Hu Zhuanglin, 2005; Li Guanxia, 2006), and the modal verbs are often used to tell different value of possibility and usuality; obligation and inclination. 
TABLE 1:

THE VALUE OF MODAL VERB

\begin{tabular}{|c|c|c|c|}
\hline & Low & Medium & High \\
\hline Positive & $\begin{array}{l}\text { can, may, could, } \\
\text { might, (dare) }\end{array}$ & $\begin{array}{l}\text { will, would, should, } \\
\text { is to, was to, shall }\end{array}$ & must, ought to, need, has/have/had to \\
\hline Negative & $\begin{array}{l}\text { needn't, doesn't/ } \\
\text { didn't+ need to/ } \\
\text { have to }\end{array}$ & $\begin{array}{l}\text { won't, wouldn't, shouldn't (isn't/wasn't } \\
\text { to) }\end{array}$ & $\begin{array}{l}\text { mustn't, oughtn't to, } \\
\text { can't, couldn't } \\
\text { (mayn't) mightn't } \\
\text { hasn't to } \\
\text { hadn't to }\end{array}$ \\
\hline
\end{tabular}

In traditional grammar, the modality is closely connected to the modal verb, which has always been an important method to achieve the modality and one of the most common and simple retrieval items for investigating the modality interpersonal meaning. In interpersonal relationships, applying different value of the modal verbs would reflect the subtle mutual relations and characters among the communicative roles. In addition, in literary texts, different subjects have totally different modality applications: the modal verbs are seldom used in poetries because the poetries focus on expressing the emotions but have rare comments; but they are used very often in narrative words and comments of prose and fictions. Therefore, this article has chosen the modality to get quantitative statistics by analyzing the modality system distribution in Major Barbara and its two Chinese translation versions by means of corpus, and analyze the typical dialogues through functional stylistics ways.

\section{THE MODAL SYSTEM AND ITS INTERPERSONAL FUNCTION IN MAJOR BARBARA}

The drama language features in colloquial and action, together with another key point, characterization. Being different from other literary styles, drama can create a typical image by narrating and describing and have double characteristics of both literary and theatrical. Time and space constraints of the stage performance have determined that the shaping of characters heavily depends on the actors lines, which has become one of the "most difficult" (said by Ying Ruocheng) problems but also a test for the author's skills. How to convey a vivid character personality, shape the drama image and set off the interrelations between the characters is the key to achieve a successful drama and translation, among which, the modality has played a role that should not be underestimated.

This article selects the climax in Scene 3(the dialogue between the Barbara and Undershaft) as the language material to study the modality distribution and functional quality in these two typical dialogues in accordance with the above table ---- The value of modal verb, and investigate the characters and their interpersonal relationship.

\section{A. Data Collection}

Input modal verbs with high value, medium value and low value respectively, e.g. must $\mid$ ought to | need | has to | have to | had to...; will | would | should | is to | was to | shall...; can | may | could | might... into "Search Term" blank in AntConc 3.2.2, and click "Start" button, then the frequency of the high value modal verbs can be found in "Concordance Hits" window while the distribution and details can be checked in "Concordance Plot" and "File View" windows just like figure 1 and figure 2 display.

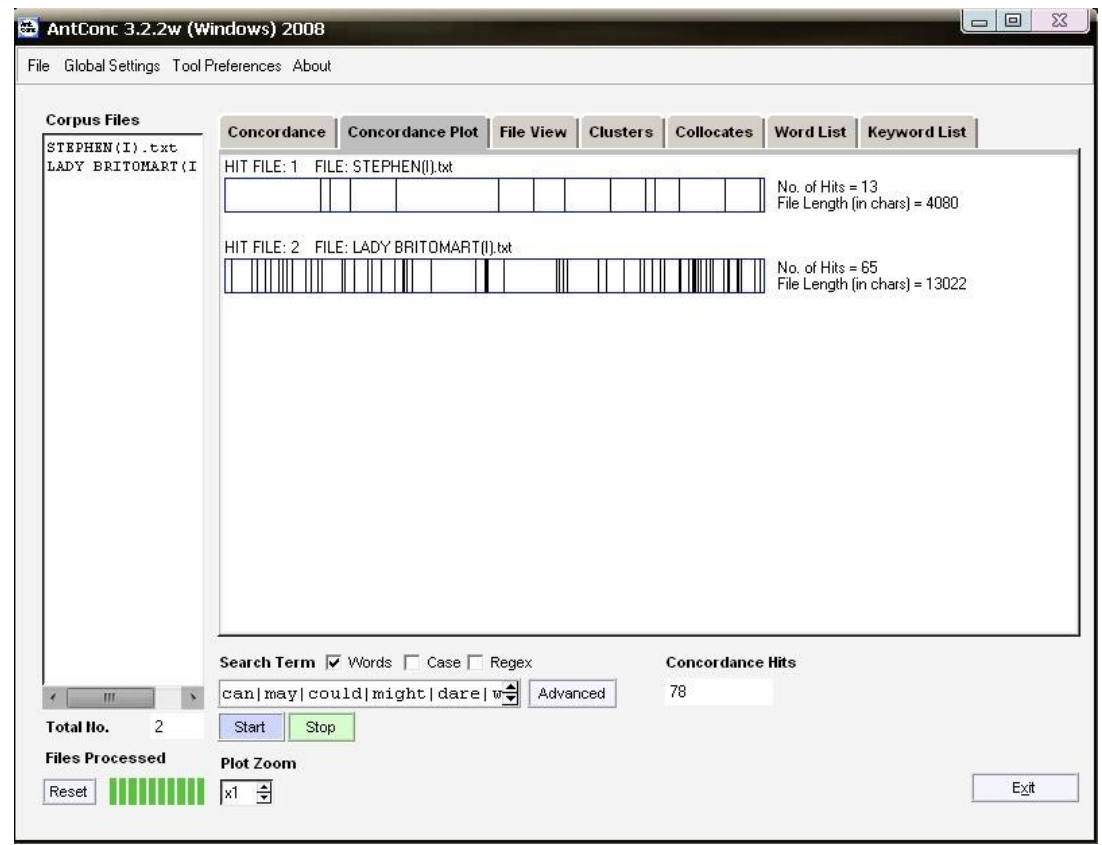

Figure 1: The distribution and frequency of the modal verbs in dialogue between Lady Britomart and Stephen 


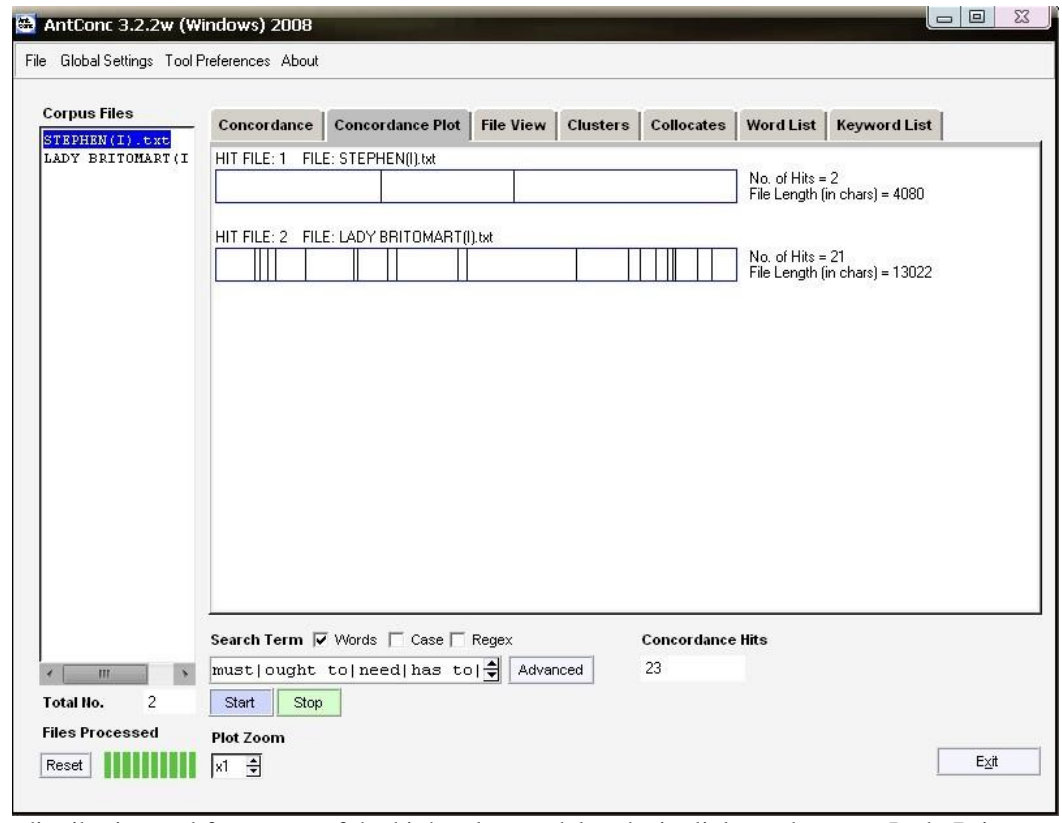

Figure 2: The distribution and frequency of the high value modal verbs in dialogue between Lady Britomart and Stephen

\section{B. Data Statistics and Tracking Investigation of Modal Verb}

The statistics have shown that in the dialogue between Lady Britomart and her son Stephen , the quantities and types of modal verbs used by Lady Britomart is more then that used by Stephen (As displayed in Figure 1: Lady Britomart used 65 times while Stephen used 13 times). Still in this dialogue, the high value modal verbs used by the mother are much more then the son (As displayed in Figure 2: Lady Britomart used 21 times while Stephen used only twice).

The high value modal verbs used by Lady Britomart includ 5 types (must, need, ought to, have/had to). Among these, the "must", which contains high mandatory occured 12 times, and 7 of them used directly to Stephen in their dialogue while 5 in that indicated compulsory provisions or restraints to her son. For example:

... You must learn to face life seriously, Stephen...

... You must advise me; you must assume the responsibility...

... you must interfere now...

... you must marry soon...

The other two musts indicated "certainly, be bound to", which showed the mother's subjective logical judgment to her son's probable situation or behaviour. For instance:

... You must know a lot of things now; unless you have wasted your time most scandalously...

... especially if you are still so childish that you must make it worse by a display of embarrassment...

Different choices for modal forms, especially the choices of high, medium and low modality can represent the attitude and force of the speaker to the proposition and the hearer so as to highlight the speaker's status and the relationship with the hearer. According to Halliday's research (1994), the speaker can use different values of modal forms to press higher or lower stress on the discourse's validity to force others to complete the instruction. High modal verbs often express strong opinions and forces in the discourse and other things or relations, reflecting certain dominance and the speaker's particular social status and personality. On the contrary, low modal forms stand for weaker opinions and forces and do not highlight the personal status and identity, but inclined to create the image as collective members.

These musts have created a strict, arrogant and vivid mother's image of high requirements for her son. Lady Britomart, as a noblewoman in high society, she developed the fastidious, arrogant and pretentious temperament. There are 13 modal verbs in Stephen's conversation here, of which contain 7 low value verbs, $53.8 \%$ of all modal verbs but only 2 high-value verbs, forming a sharp contrast to the mother's words from amounts or types. Thus, the audiences will clearly feel the son's submissive personality and then construct a primary image of the two characters' relationship and status in this family.

There are still 3 musts that reflect Lady Britomart high willingness for her own obligations. For example:

... I must get the money somehow...

... So I must put my pride in my pocket and ask for it...

... You mean that I must ask him...

The high-value modal verb "must" here have fully revealed that Lady Britomart is not only a strict mother, but also a loving mother showing the utmost solicitude to her son. When dealing with the children's living difficulties, she has taking responsibility as a mother to ask for the money, which she does not care but can not reject, from her husband who has been separated for a long time despite the upper-class lady's status. 
However, when referring to the husband Undershaft, the two "must" and "had to" are high-value ones meaning "surely" and "cannot but, which imply high possibility and obligation. It is clear that though they have been separated for many years, she is still confident that she understands her husband well and is sure about his material and spirit life, so her tone is certain and holds a tough stance. Audiences are able to imagine and infer that Lady Britomart might be arrogant to the husband and must have a higher status in the family and before separation. Thus, further guess about the subtle connections between the separation and their characters, background and status can be made. Meanwhile, the audiences can also infer that Lady Britomart has to come off her perch and respect Undershaft well but would not be too humble in the following texts. For example:

... Stephen, your father must be fabulously wealthy...

... But he thinks I ought to ask Andrew to come here and see the girls. After all, he must have some natural affection for them.

... always awkward and sullen when he had to behave sensibly and decently!

... Andrew had to contribute something.

In the other reference group ---- dialogue between Undershaft and Barbara:

The father, Undershaft, has used more modal verbs than the daughter Barbara in number and type (Undershaft: 19times; Barbara: 5 times), and they differ a lot in the frequency of using medium-value modal verb (Undershaft: 15 times; Barbara: 3 times).

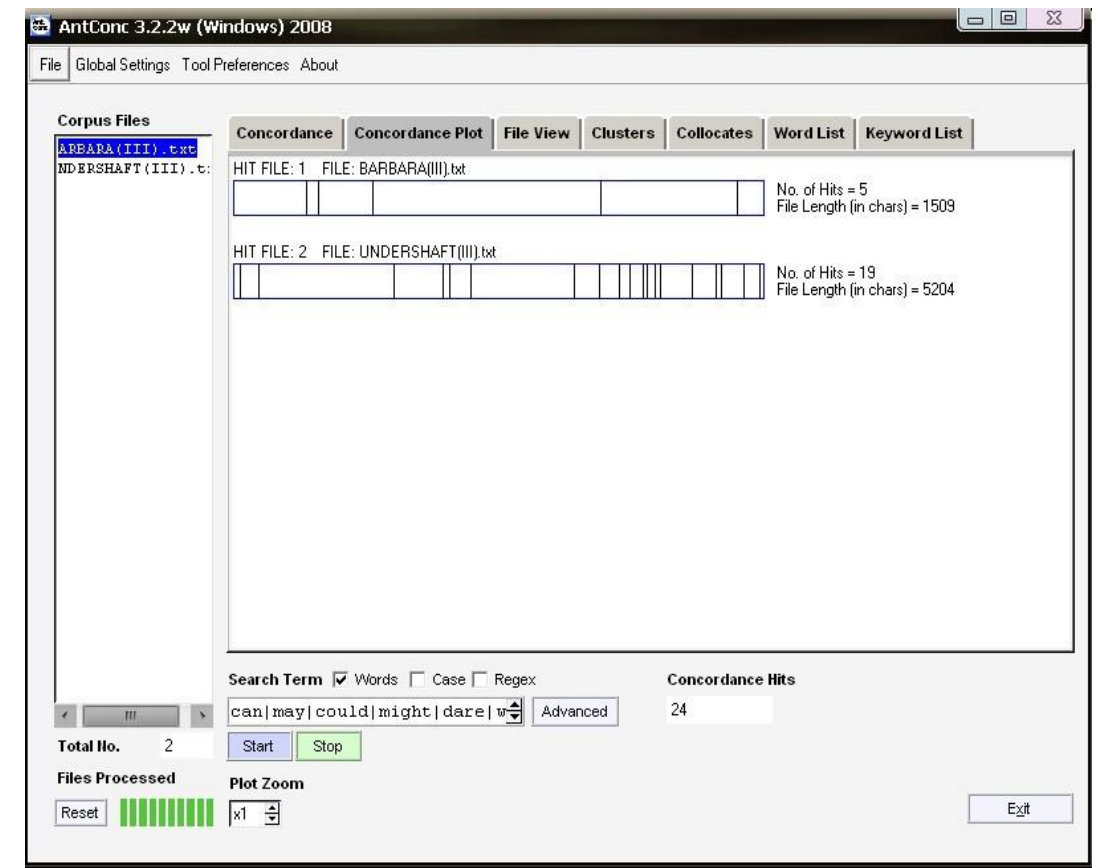

Figure 3: The distribution and frequency of the modal verbs in dialogue between Undershaft and Barbara 


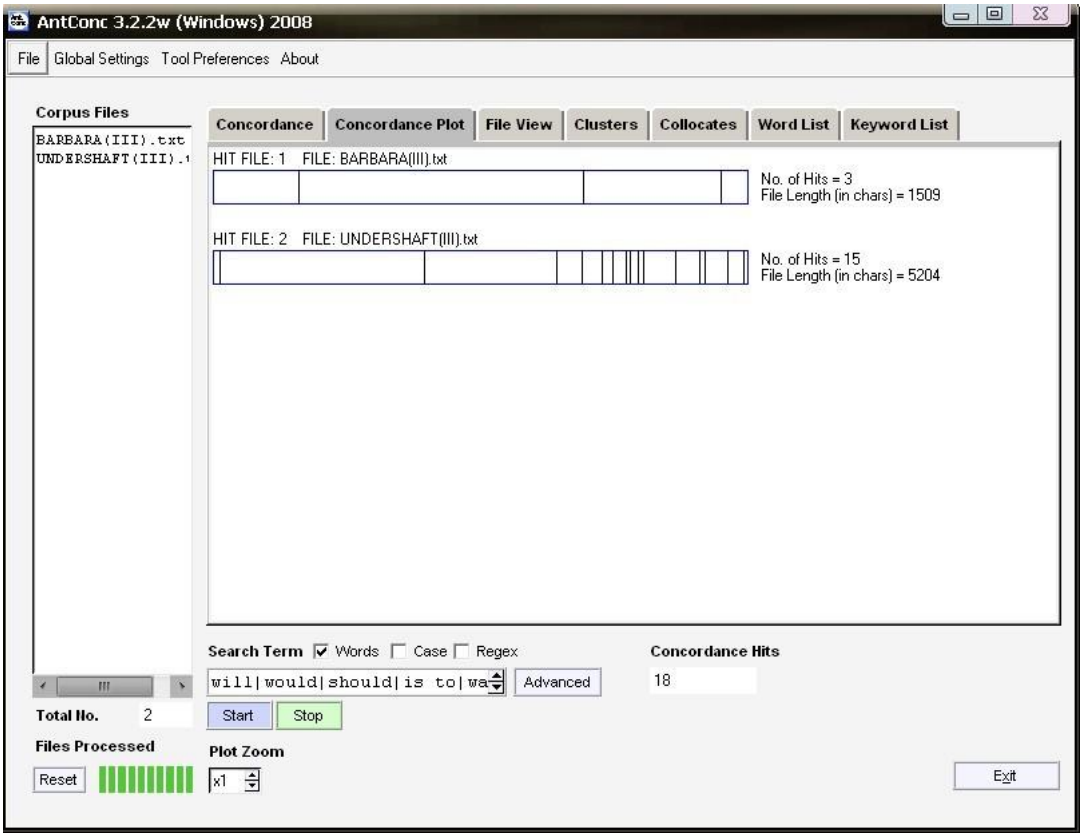

Figure 4: The distribution and frequency of the medium value modal verbs in dialogue between Undershaft and Barbara

It can be found out from Figure 3 and 4 that the father and the daughter use medium-value modal verbs most. The high-value "had to" (... When I joined it, I had not time enough for all the things I had to do.), representing "obligation" is only used once in the dialogue when Barbara starts the passive conversation because of the father's question. The emergence of high-value modal verbs implies Barbara's complex feelings of shocking, disappointed and angry after hearing that her fiancé discuss about the powder mill's inherence, while the father's question gives her a chance to express her inner feelings. "Had to" means "cannot but", and Barbara, who has always been sincere about the Salvation Army doctrine, describes the army affairs as something "had to do" but not from the heart. This is strange and need careful consideration. The audiences may find that her value has been affected and is changing gradually.

Barbara has used medium and low value modal verbs for 4 times besides the above high-value one in the dialogue. They are:

... Yesterday I should have said, because I was in the power of God.

... Oh how gladly I would take a better one to my soul! But you offer me a worse one.

... And will he be the better for that?

... Today I feel—oh! How can I put it into words?

As a medium-value modal word, "should" indicates "obligation" and not very sure; "would" is a medium-value predictive word, implies an imagine scene; "will" means the objective and certain guess for the future. The three words constitute $3 / 5$ of Barbara's words in this paragraph, so we know that she is not sure about her idea and her faith is not firm. "Can" means "lower possibility", which shows Barbara's idealism belief has been damaged by her father's harsh economic reality and defeated in the conflicts with the father. Her complex emotion is beyond words description. Though they have not seen for many years, the father's performance in this meeting has a great effect on her and becomes the turning point of her belief and a vital change in her life.

It is noteworthy that father Undershaft has used abundant modal words without any high-value modal verbs but only medium and low value verbs. For example:

... I will take an order from a good man as cheerfully as from a bad one.

... I took care that you should have money enough to live handsomely - more than enough; so that you could be wasteful, careless, generous.

... Nothing can lift those seven millstones from Man's neck but money

... and I will drag his soul back again to salvation for you.

... He will be better fed, better housed, better clothed, better behaved; and his children will be pounds heavier and bigger.

... That will be better than an American cloth mattress in a shelter...

... I will undertake to convert West Ham to Mohammedanism...

As mentioned above, low modal verbs stand for weaker opinions and forces and do not highlight the personal status and identity, but inclined to create the image as collective members. Now though holding the discourse advantage, Undershaft has used a lot of medium and low value verbs. His attitude is tough but the expression is mild and the tone is soft and full of caring, acting as a kind father. Showing more intimate and gentle kindness, he just wants to be closer to his daughter. On the one hand, he hopes to make up the unpaid love between father and daughter; on the other hand, this makes bedding for persuading the daughter to change her thought. 
Figure 3 and 4 also illustrate that the modal verbs are not evenly distributed, particularly the frequency by Undershaft is obviously going high and most modal verbs especially the medium-value verbs are centered in the end of conversations. It is not difficult to see that the father and the daughter have experienced mood swing and discourse power change: Undershaft is in high spirit and his sentences become longer with more high-value modal verbs and higher discourse power; while Barbara is retreating again and again and her sentences become shorter with more low-value verbs and unable to refute father's opinions, and her faith is shaking.

\section{The COMParison to the Original on Usage Rule of CAN-Wish Verbs in Two Chinese Translation VERSIONS OF MAJOR BARBARA}

There are various ways to express the mood in Chinese as in English, and the core element is can-wish verbs. Peng Xuanwei (2000) has classified the values of can-wish verbs, referring to Halliday's dividing way in English modal operators: low-valued can-wish verbs such as “能，会，可以，不会，可能不，不能够...”; medium can-wish verbs such as “想，要，想要，不想，不愿...”; high-valued verbs like “得，应该，要，不可能，不可以，不能，不 得...”According to the feature of the Chinese characters used in the chosen materials, can-wish verbs in the two Chinese versions of Major Barbara, translated by Lin Haozhuang (Hereinafter referred to as Lin) and Ying Ruocheng (Hereinafter referred to as Ying) can be classified as follow:

TABLE 2:

THE TYPES OF CAN-WISH VERBS IN TWO CHINESE TRANSLATION VERSIONS OF MAJOR BARBARA

\begin{tabular}{|l|l|l|l|}
\hline $\begin{array}{l}\text { Chinese } \\
\text { translation } \\
\text { version }\end{array}$ & Low-value can-wish verb & Medium-value can-wish verb & High-value can-wish verb \\
\hline Lin & $\begin{array}{l}\text { 会、能、可以、能够、不会、 } \\
\text { 不一定 }\end{array}$ & $\begin{array}{l}\text { 想、要、不要、就要、应当 } \\
\text { Ying }\end{array}$ & $\begin{array}{l}\text { 会、得、要、该、一定、不可、不能、 } \\
\text { 定、应该、不得不 }\end{array}$ \\
\hline
\end{tabular}

\section{A. Data Collection}

According to the classification mentioned above, input can-wish verbs with high value, medium value and low value respectively, e.g. 得|应该|要|不可能|不可以|不能|不得...; 想|要|想要|不想|不愿...; 能|会|可以|不会|可能不|不能 够... into “Search Term" blank in AntConc 3.2.2, and click "Start" button, then the frequency of the high value modal verbs can be found in "Concordance Hits" window while the details can be checked in "File View" windows. Relevant data can be concluded in Table 3:

TABLE 3:

THE COMPARISON TO THE ORIGINAL ON THE FREQUENCY OF MODAL VERBS (CAN-WISH VERBS) IN TWO CHINESE TRANSLATION VERSIONS OF MAJOR BARBARA

\begin{tabular}{|c|c|c|c|c|c|c|c|c|c|}
\hline \multirow{2}{*}{ Character } & \multicolumn{3}{|c|}{ Low-value can-wish verb } & \multicolumn{3}{|c|}{ Medium-value can-wish verb } & \multicolumn{3}{|c|}{ High-value can-wish verb } \\
\hline & Original & Lin & Ying & Original & Lin & Ying & Original & Lin & Ying \\
\hline $\begin{array}{l}\text { Lady Britomart } \\
\text { (薄丽托玛夫人 } \\
\text { /薄丽托马夫人) }\end{array}$ & 16 & 18 & 16 & 28 & 13 & 25 & 21 & 23 & 34 \\
\hline $\begin{array}{l}\text { Stephen } \\
\text { (斯泰芬/斯蒂文) }\end{array}$ & 7 & 7 & 7 & 4 & 2 & 3 & 2 & 0 & 4 \\
\hline $\begin{array}{l}\text { Barbara } \\
\text { (巴巴娜/芭巴拉) }\end{array}$ & 1 & 0 & 3 & 3 & 1 & 1 & 1 & 1 & 3 \\
\hline $\begin{array}{l}\text { Undershaft } \\
\text { (安德谢夫) }\end{array}$ & 3 & 11 & 7 & 15 & 2 & 7 & 1 & 3 & 1 \\
\hline
\end{tabular}

\section{B. The Interpersonal Function Analysis of the Can-wish Verbs in Drama Translation}

Summing up the above data, the two versions have obvious similarities and partial differences compared with the original work on the usage rule of different value's can-wish verbs. The disparity of the three texts is very small in the numbers of Lady Britomart's low-value verbs, Stephen and Barbara's can-wish verbs and Undershaft's high-value verbs, even achieving exactly the same on Stephen's low-value can-wish verbs. The data in this sheet intuitively indicate that the two translators have taken the original's language features into consideration, seizing the usage rule of modal verbs and mastering the characters' features, to rebuild the interactive relationship between characters successfully.

The differences in the sheet most exist in Lady Britomart's medium and high value verbs and Undershaft's low and medium value can-wish verbs. Ying's version uses more high-value verbs than the original work and Lin's version, but the numbers of medium-value verbs are closer to the original. In this comparison, Lin's version displays a totally different feature: Lin's Undershaft uses more low-value verbs than the original and Ying's version, but the medium-value verbs are less than that two. In general, Ying's usage rule of can-wish verbs is much closer to the 
original.

According to the second part of this article, in the opening of the first act, Bernard Shaw attempts to describe Lady Britomart's strict, arrogant and responsible mother image, attaching fastidious, proud and pretentious features to her. Compared with Lin's version, Ying adopts more numbers and types of high-value can-wish verbs to make this classic noble mother image become richer and more vivid.

Lin uses a lot of low-value can-wish verbs in Undershaft's conversation with his daughter in the third act's climax, aiming to weakening the role's personal views and power, not to highlight his status and identity, but to create the image as a collective member. This version intends to depict Undershaft as a persuasive and loving father who hope to improve the relationship with the daughter.

As shown in Table 4, by comparing the total usage numbers of modal verbs in the original with the two Chinese translation versions, we can find that Ying uses more can-wish verbs than the original to highlight the noble mother's image. While other role's usage numbers are very near to the original work, maintaining the original language style and the character features and properly analyzing the interpersonal relationship. Generally speaking, Lin's version is closer to Shawn's original modality.

TABLE 4:

THE COMPARISON TO THE ORIGINAL ON THE TOTALITY OF MODAL VERBS (CAN-WISH VERBS) IN TWO CHINESE TRANSLATION VERSIONS OF MAJOR

\begin{tabular}{|l|l|l|l|}
\hline Character & Original & Lin & Ying \\
\hline $\begin{array}{l}\text { Lady Britomart } \\
\text { (薄丽托玛夫人 } \\
\text { /薄丽托马夫人) }\end{array}$ & 65 & 54 & 75 \\
\hline $\begin{array}{l}\text { Stephen } \\
\text { (斯泰芬/斯蒂文) }\end{array}$ & 13 & 9 & 14 \\
\hline $\begin{array}{l}\text { Barbara } \\
\text { (巴巴娜/芭巴拉) }\end{array}$ & 5 & 2 & 7 \\
\hline $\begin{array}{l}\text { Undershaft } \\
\text { (安德谢夫) }\end{array}$ & 19 & 16 & 15 \\
\hline Total & 102 & 81 & 111 \\
\hline
\end{tabular}

\section{CONCLUSIONS}

The different expression ways and forms between English and Chinese have caused different specific forms of modality system in them. English is such a language requiring strict sentence structure and the pattern as its main axis, so the modal expression mainly depends on the modality system with relatively fixed grammar function; while Chinese emphasizes the function and diversity of language with the motivation as its core, thus the ways of expressing modality are more flexible. In general, modal (can-wish) operators (verbs) are the major marks both in English and Chinese modality system. When we are creating or translating drama, the choices of modal forms (especially the high, medium and low value verbs) play a subtle regulating role in expressing the speaker's attitude and power relation towards the discourse and the hearer, thus the speaker's status and the characters' interrelations can be more prominent. Therefore, analyzing the drama and its translation from the modal verbs can help us catch the key point of the character communication, accurately understand the interrelations, analyze the psychological changes and improve the reconstruction ability of character personality and interrelationship in drama translation. Furthermore, the corpus functional stylistics has provided an effective and new perspective to study drama translation which is worthy for further research.

\section{REFERENCES}

[1] Anthony, L. (2011). AntConc (Version 3.2.2) [Computer Software]. http://www.antlab.sci.waseda.ac.jp/ (accessed 27/9/2009).

[2] Boase Beier J. (2004). Translation and Style: A Brief Introduction. Language and Literature, 13 (3), 9-11.

[3] Bennison, V. (1993). Discourse analysis and the dramatic character. Journal of Language and Literature, 2, 32-39.

[4] Carter, R. \& Simpson, P. (eds.). (1989). Language, Discourse and Literature: An Introductory Reader in Discourse Stylistics. London: Unwin Uyman.

[5] Halliday, M. A. K. (1994). An Introduction to Functional Grammar. London: Edward and Arnold/ Beijing: Foreign Language Teaching and Research Press.

[6] Herman, V. (1995). Dramatic Dialogue: Dialogue as Interaction in Plays. London: Routledge.

[7] Hu Zhuanglin. (2005). Introduction to Systemic Functional Linguistics. Beijing: Peking University Publishing House.

[8] Kruger, A. (2000) Lexical Cohesion and Register Variation in Translation: The Merchant of Venice in Afrikaans. Pretoria: University of South Africa.

[9] Kruger, A. (2004) Shakespeare in Afrikaans: A Corpus-based Study of Involvement in Different Registers of Drama Translation. Language Matters, 35(1), 282-301.

[10] Li Guanxia. (2006). A Course-book on Functional Grammar. Beijing: Foreign Languages Press.

[11] Pan Jiaxu and Lin Haozhuang. (1963). Three of Bernard Shaw Plays. Beijing: People's Literature Publishing House.

[12] Peng Lizhen. (2007). Study on Modality of Modern Chinese. Beijing: China Social Sciences Publishing House. 
[13] Peng Xuanwei. (2000). A Comparison between English and Chinese Discourse. Shanghai: Shanghai Foreign Language Education Press.

[14] Ren Xiaofei. (2008). A Systematic Study on Ying Ruocheng's Drama Translation. Beijing: China Social Sciences Publishing House.

[15] Shen Dan. (2008). The New Development of The Western Stylistics. Shanghai: Shanghai Foreign Language Education Press.

[16] Shen Dan. (2000). The Development of Western Modern Stylistics in A Century. Foreign Language Teaching and Research, 1, $22-28$.

[17] Shen Dan. (1995). Literary Stylistics and Fictional Translation. Beijing: Peking University Publishing House.

[18] Toolan, M. (1998). Language In Literature: An Introduction To Stylistics. USA: Oxford University Press.

[19] Wu Shuqiong. (2009). Review and Prediction on English Model Verb's Study. Journal of Hubei University of Education, 3 , 21-22.

[20] Ying Ruocheng. (1999).Ying Ruocheng Drama Translations. Beijing: China Translation and Publishing Corporation.

[21] Yu Dongming. (1996). Drama Style and Drama Stylistics, Journal of Zhejiang University, 1, 37-42.

[22] Yu Tao and Wang Yun. (2008).A Contrastive Analysis of the Grammatical Meaning of Engllish and Chinese Modal Verbs. Journal of Xuzhou Normal University, 4, 66-69.

[23] Zhang, R. E. \& Chen, D. Y. (2010). Focusing on the Function of Modality - A Stydy on the Modality System in Discourse and the Functional Construction in Translation. Foreign Language and Literature Studies, 1, 42-47.

[24] Zhu Guanming. (2003). Mechanisms of Meaning Extension of the Chinese Monosyllabic Modal Auxiliaries. Journal of PLA University of Foreign Languages, 6, 43-48.

Zan Mao was born in Zhenjiang, China in 1985. She received her M.A. degree in foreign liguistics and applied linguistics from Jiangsu University, China in 2012.

She is currently an assistant in English Department, Zhenjiang Watercraft College of PLA, Zhenjiang, China. Her research interests include Second Language Acquisition and Foreign Language Teaching.

Na Li was born in Zhenjiang, Jiangsu, China in 1982. She received her bachelor degree in linguistics from Guilin Industrial Colle ge China in 2006.

She has been teaching English for 6 years in Watercraft College, Zhenjiang. Her research interests include English Linguistic and Literature Translation.

Jiao Xue was born in Yangzhou, China in 1986. She received her M.A. degree in foreign liguistics and applied linguistics from Jiangsu University of Science and Technology, China in 2011.

She is currently a tutor in Foreign Language Department, Zhenjiang Watercraft College, Zhenjiang, China. Her research interests i nclude second language acquisition and intercultural communication. 